\title{
The immunohistochemical analysis of fibronectin, collagen type III, laminin, and cytokeratin 5 in putrified skin
}

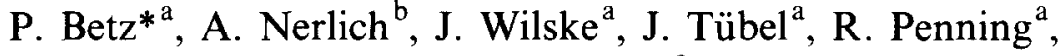 \\ W. Eisenmenger ${ }^{\mathrm{a}}$ \\ ${ }^{a}$ Department of Legal Medicine, ${ }^{b}$ Department of Pathology, University of Munich, Frauenlobstr. $7 a$, \\ 80337 Munich 2, Germany
}

(Received 8 January 1993; revision received ; accepted 14 March 1993)

\begin{abstract}
Fibronectin, collagen type III, laminin, and cytokeratin 5 were visualized in normal skin and in skin showing early or advanced signs of autolytic decomposition to prove whether the immunohistochemical analysis of these antigens can provide useful information for an ageestimation of skin wounds obtained from putrified corpses. In cases with early signs of decomposition (visible course of veins, greenish discoloration) and without microscopic alterations like relaxation of the epidermal cell layers or destruction of the blood vessel structures, the staining pattern was identical to that found in normal, non-putrefied skin. In skin already showing microscopic alteration of the tissue structure, fibronectin and collagen type III could not be localized unambiguously. The distribution of laminin and cytokeratin 5 , however, was well preserved. In advanced putrefied skin no reliable staining results could be obtained for fibronectin, collagen type III, and laminin. Even though cytokeratin 5 was still detectable in remnants of decomposition-resistant skin appendages, no information useful for an ageestimation of skin wounds can be obtained due to the autolytic detachment of the epidermal layers.
\end{abstract}

Key words: Immunohistochemistry; Putrefaction; Fibronectin; Collagen type III; Laminin; Cytokeratin 5

* Corresponding author.

0379-0738/93/\$06.00 (C) 1993 Elsevier Scientific Publishers Ireland Ltd. All rights reserved. SSDI 0379-0738(93)01319-M 


\section{Introduction}

The application of immunohistochemical techniques has considerably improved forensic histology. For example the detection of C 5b-9-complement-complexes can be used for an early diagnosis of ischemic myocardial necrosis [1]. By immunostaining, blood group substances have been analysed in tissues [2]. In addition, immunohistochemistry provides useful information for toxicological examination [3-5] and for the determination of vitality of skeletal muscle trauma [6].

Up to now almost all reports - with the exception of Pedal and Baedecker [7] who localized $\mathrm{A}, \mathrm{B}$, and $\mathrm{H}$ isoantigens in putrefied kidneys - dealt with the analysis of antigens in non-putrified material. On the other hand, in forensic medicine putrefied tissues also have to be evaluated and, therefore, investigations concerning the stability of antigens in the postmortem interval are necessary.

In the present study, antigens of various protein groups were analyzed in skin showing early or advanced signs of decomposition by immunohistochemistry. This study was undertaken to supplement our previous studies dealing with the immunohistochemical age-estimation of human skin wounds [8-13].

\section{Materials and methods}

Fibronectin, collagen type III, laminin, and cytokeratin 5 were localized in normal skin by immunohistochemistry according to the $\mathrm{ABC}$-method [14] as previously described [8,10-12]. Furthermore, these antigens were analyzed in skin specimens obtained from 20 corpses with a postmortem interval between 3 days and 6 weeks showing signs of early (visible course of veins, greenish discoloration of the skin; $n=10$ ) or advanced (greenish-purplish-brown discoloration of the skin, detachment of the epidermis; $n=10$ ) putrefaction.

\section{Results}

\subsection{Normal skin}

Fibronectin. A weak diffuse staining for fibronectin was observed in the dermis and a strong reactivity could be found near the basement membrane of the epidermis, of skin appendages, blood vessel endothelium, nerve and muscle cells.

Collagen type III. The dermis showed a diffuse staining with a pronounced reactivity in the stratum papillare. Furthermore, a distinct positive reaction could be observed near the basement membrane of the epidermis, of skin appendages, blood vessel endothelium, nerve and muscle fiber bundles.

Laminin. A strong, selective reactivity was found in the basement membrane of the epidermis, skin appendages, blood vessel endothelium, nerve and muscle fiber bundles.

Cytokeratin 5. In normal skin only the basal cell layer of the epidermis and basal cells of the epithelium of skin appendages like sweat gland ducts reacted strongly.

\subsection{Early putrefaction}

$H-E$ staining. In some specimens the normal tissue structure was still quite well 


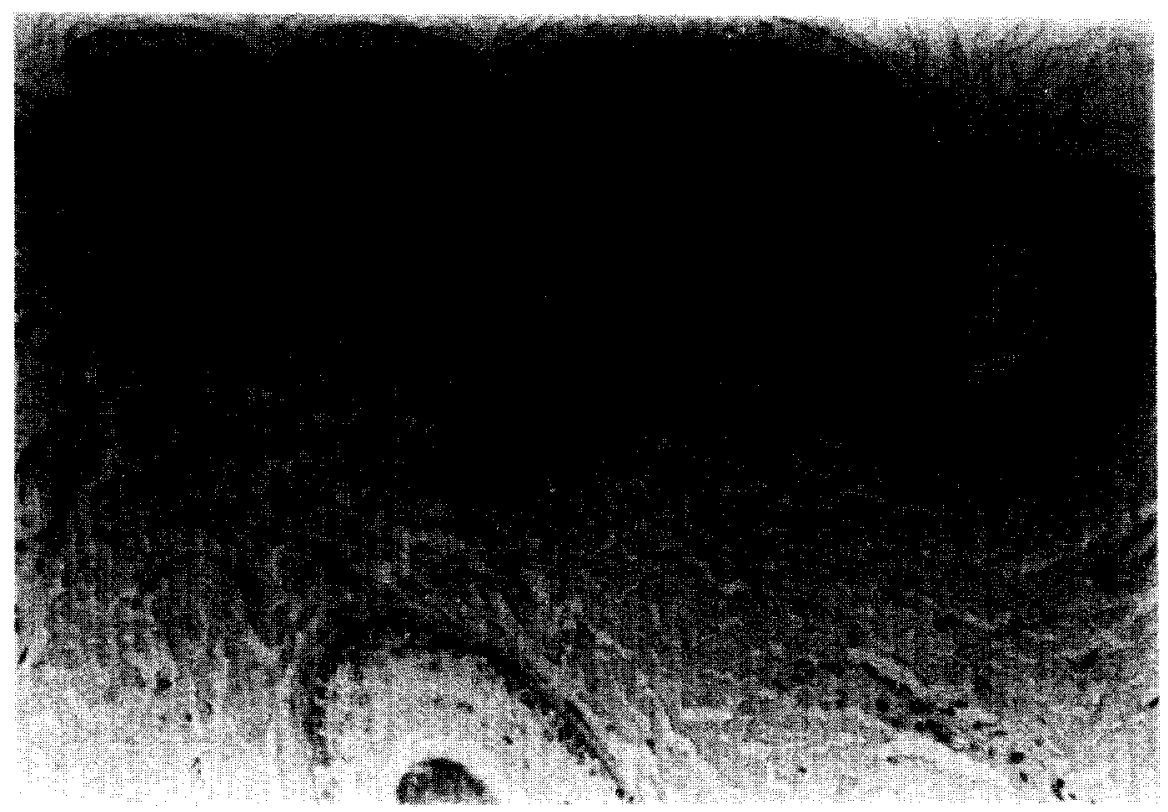

Fig. 1. Normal skin: pronounced reactivity for collagen type III near basement membranes, especially of the epidermis (see arrows). (ABC-method, paraffin, $\times 190$ )

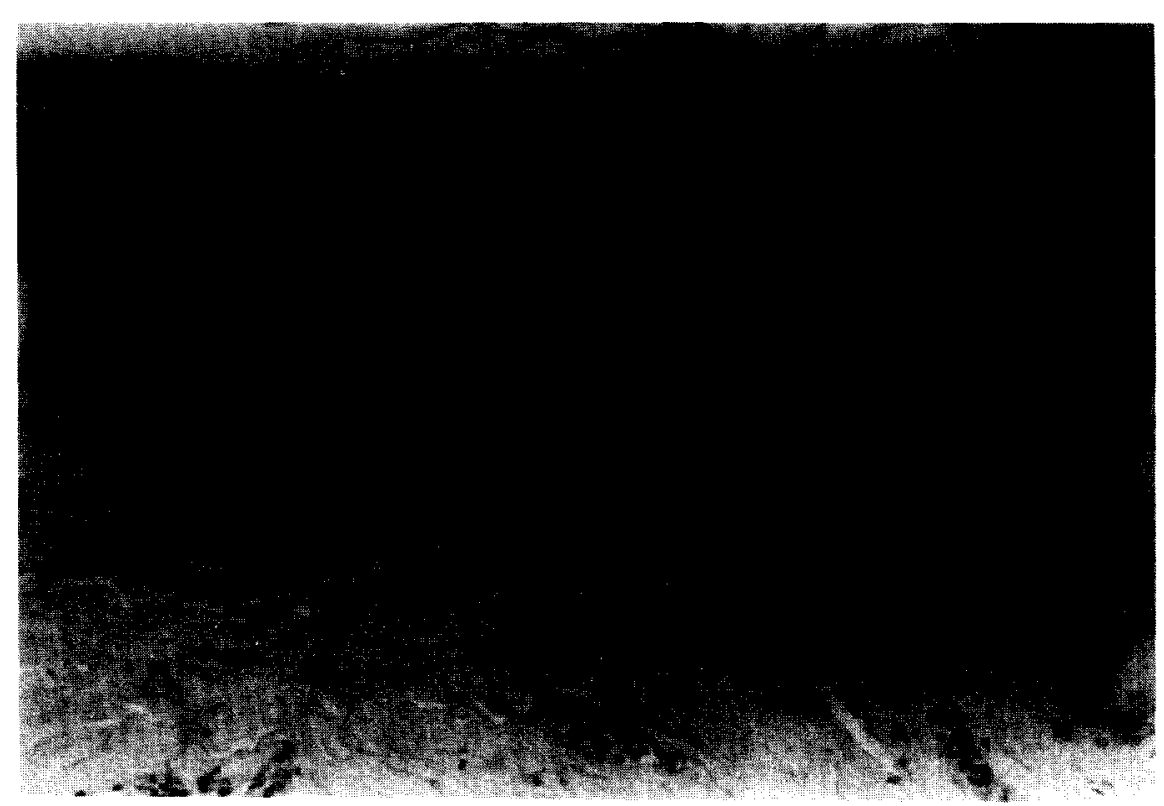

Fig. 2. Skin showing early putrefaction (relaxation of the epidermal cell layers and blood vessels): no positive staining for collagen type III near the epidermal basement membrane. (ABC-method, paraffin, $\times 190$ ) 


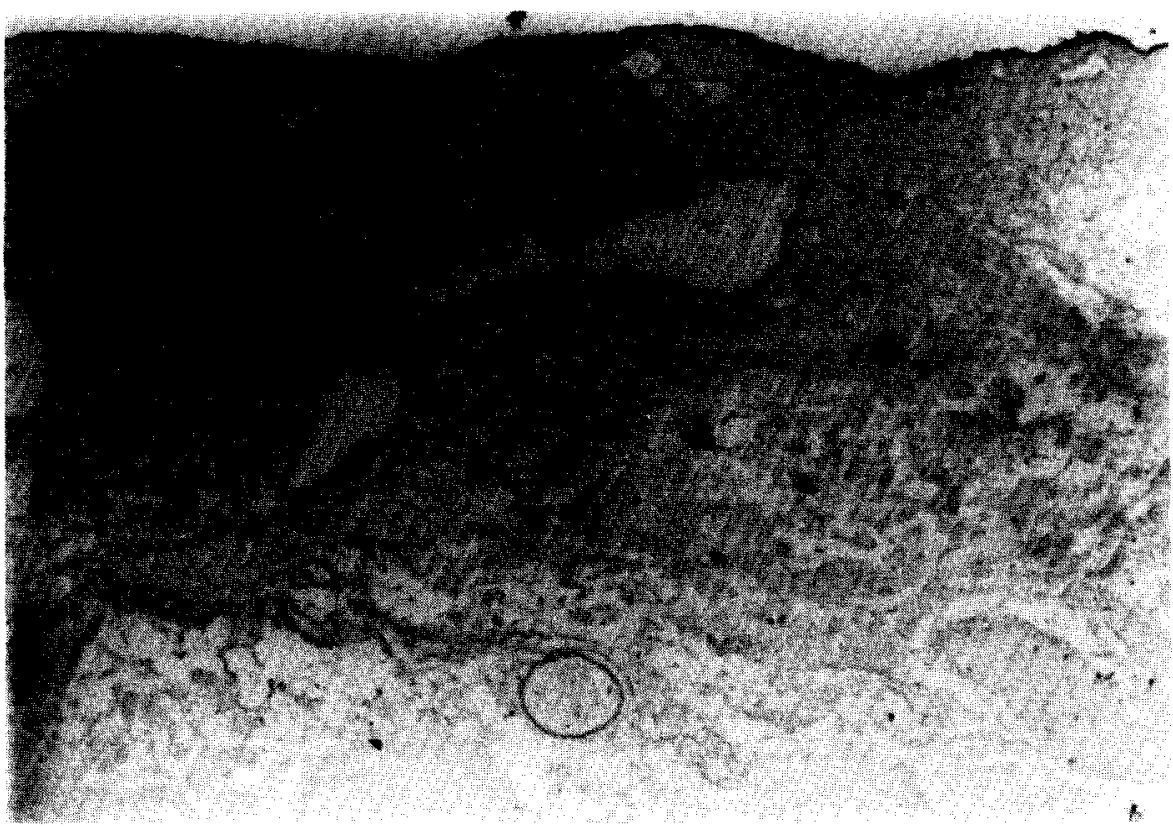

Fig. 3. Advanced putrefied skin: no distinct specific staining for collagen type III, unspecific band-shaped 'reaction' on the upper margin of the corium. (ABC-method, paraffin, $\times 190$ )

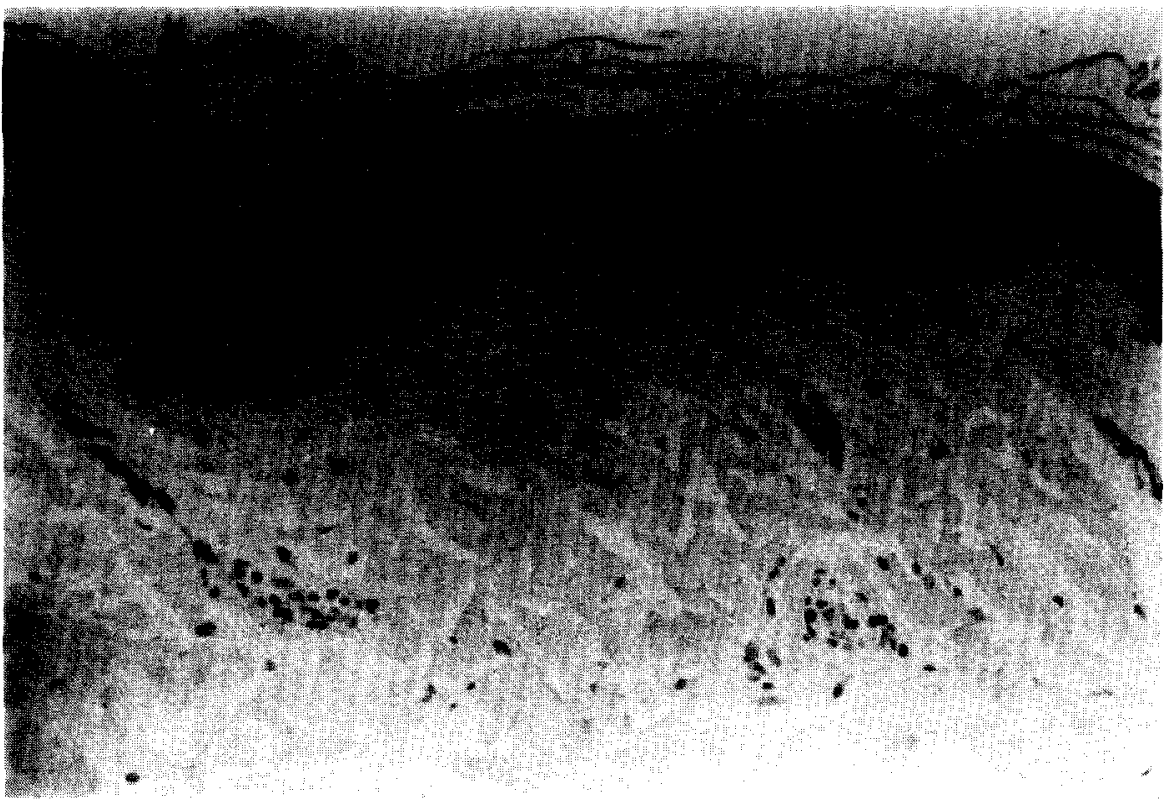

Fig. 4. Normal skin: strongly positive reaction of the basal cells of the epidermis for cytokeratin 5. (ABCmethod, paraffin, $\times 190$ ) 


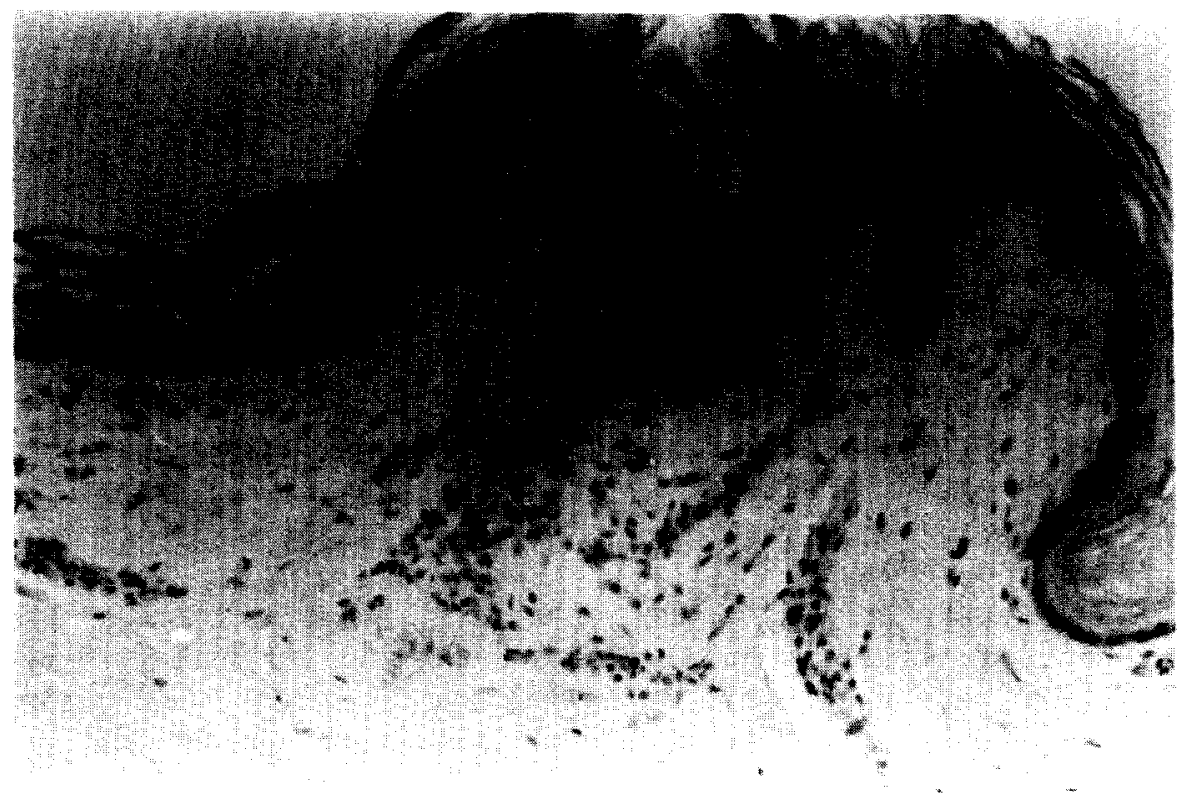

Fig. 5. Slightly putrefied skin (sec also Fig. 2): well prescrved positive staining of the basal cells of the epidermis showing a relaxation of the different cell layers. (ABC-method, paraffin, $\times 190$ )

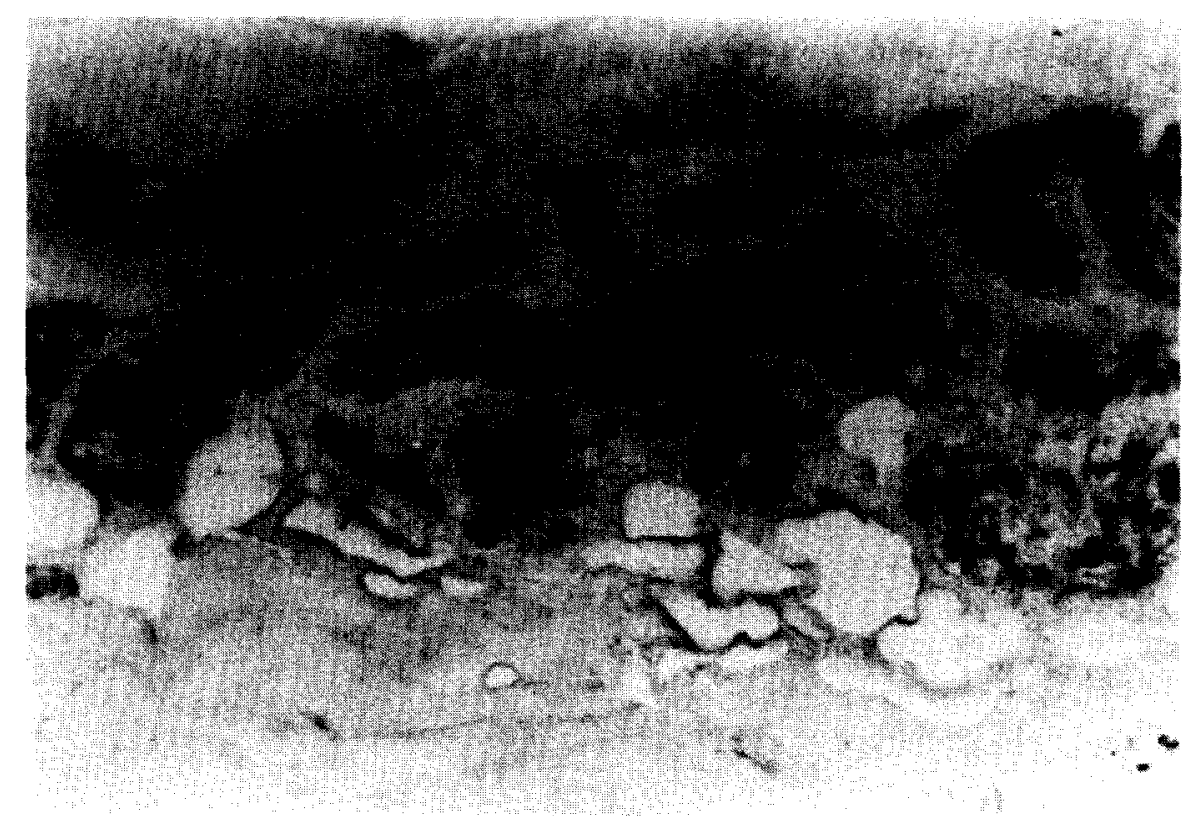

Fig. 6. Advanced putrefied skin (see also Fig. 3): few cells of sweat gland ducts still showing a positive reaction for cytokeratin 5 (see arrows). (ABC-method, paraffin, $\times 190$ ) 
preserved, in other areas, however, the epidermis and especially blood vessel walls showed a slight relaxation of the respective cell layers and a reduced staining intensity of the nuclei localized in these areas.

Fibronectin and collagen type III. In skin specimens showing a well preserved tissue structure a staining pattern was found identical to that of normal skin. In cases with more intense alterations no specific localization of fibronectin and collagen type III was possible since a somewhat enhanced background staining and a considerably reduced intensity of the specific reaction was found.

Laminin and cytokeratin 5. In all specimens an identical staining pattern was observed as in non-putrified skin. In some cases a slightly reduced, but distinct staining intensity for cytokeratin 5 occurred in areas in which a relaxation of the epidermal cell layers could be detected.

\subsection{Advanced putrefaction}

$H-E$ staining. In these cases the whole epidermis was detached. The blood vessels were identifiable only as silhouettes, no cell structures could be found. Morphological details of nerve or muscle cells could hardly be observed, but in some specimens the structure of skin appendages could still be identified, even though the cell layers showed also a considerable relaxation.

Fibronectin and collagen type III. The dermis was characterized by a diffuse (unspecific) staining, no distinct reactivity was seen near the fading structures of blood vessels, nerve or muscle fibers or around skin appendages. The upper margin of the dermis adjacent to the now detached epidermis showed a band-shaped enhanced homogenous 'reaction' due to unspecific staining.

Laminin and cytokeratin 5. Comparable to the results obtained for fibronectin and collagen type III, a band-shaped staining pattern near the former dermo-epidermal junction was observed for laminin, but not for cytokeratin 5. No distinct reaction for laminin could be detected near the silhouettes of blood vessels, of nerve or muscle fiber bundles nor of skin appendages. In some specimens, however, basal cells of rather well preserved and apparently decomposition-resistant skin appendages like sweat glands revealed a positive staining for cytokeratin 5 .

\section{Discussion}

The use of histological techniques in forensic medicine is limited by autolytic decomposition of the morphological structures. Immunohistochemistry, especially, has been assumed to be rather sensitive to tissue decay due to the decomposition of the respective antigens whereas enzyme histochemistry of the skin is characterized by a considerable resistance to putrefaction $[15,16]$.

Immunohistochemical methods seem to be influenced by several mechanisms occurring during putrefaction. The decomposition of proteins thus leads to a destruction of the antigenic structure and a 'diffusion' of antigens from their normal localization, due to the autolytic relaxation of the tissue structure, can occur. In addition, the unspecific binding of antibodies increases in putrified tissues due to the presence of disrupted protein structures leading to an enhanced unspecific background staining. All these factors limit the use of immunohistochemical tech- 
niques for the evaluation of putrified material. On the other hand, Pedal and Baedecker [7] localized A, B, and $\mathrm{H}$ isoantigens in the collecting tubular epithelium in advanced putrefied kidneys indicating the possibility that some antigens may be detected in spite of advanced putrefaction.

In our material, all antigens could be localized in skin showing slight macroscopic (visible course of veins, greenish discoloration) but no microscopic (relaxation of cell layers of the epidermis or blood vessels) signs of decomposition. If microscopic changes were present, fibronectin and collagen type III showed a considerably reduced reactivity with a somewhat enhanced unspecific background staining allowing no reliable localization of these antigens. The distribution of laminin or cytokeratin 5 , however, seemed better preserved and identical to that found in non-putrefied skin. These results indicate a higher decomposition-resistance of laminin and cytokeratin 5 in comparison to fibronectin and collagen type III. This observation can perhaps be explained by the hypothesis that the antigen structures of laminin and cytokeratin 5 appear to be 'unmasked' by the early putrefaction resembling the 'enzymatic pretreatment' which is usually performed during immunohistochemistry. This hypothesis is supported by the observation that, in particular, basement membrane components need a more aggressive enzymatic pretreatment to enhance immunoreactivity when compared to fibronectin or collagen type III (Betz, P. et al., unpublished results.

In advanced putrefied skin, a localization of laminin was also impossible, but cytokeratin 5 was still detectable in a somewhat reduced staining intensity in skin appendages showing a rather well-preserved cell architecture. This observation could support the hypothesis of a high decomposition-resistance of this antigen type. But on the other hand, no information useful for a wound age-estimation can be obtained by the immunohistochemical analysis of cytokeratin 5 in advanced putrefied skin since the cpidermal laycrs are detached and can therefore not be cvaluated.

\section{Conclusion}

The immunohistochemical localization of various antigens useful for an ageestimation of human skin wounds can also provide information in cases of early putrefaction, especially the localization of laminin and probably of other basement membrane components and of cytokeratins. Interstitial collagen types and cell adhesion molecules, however, seem to be more sensible for decomposition and a reliable localization of these proteins in skin showing microscopic signs of putrefaction cannot be performed.

In advanced stages of putrefaction of the skin, immunohistochemical staining methods seem to reveal no significant results due to the destruction of the antigen structure and/or of the general tissue morphology.

\section{Acknowledgements}

This study was supported by a grant from the 'Deutsche Forschungsgemeinschaft' (grant Nos. Be 1555/1-1 and Be 1555/1-2) and by a grant from the 'Friedrich-BaurStiftung, University of Munich. 


\section{References}

1 H. Thomsen, A. Schulz and S. Bhakdi, Immunhistochemische C 5b-9-Komplement-Komplex Darstellung in Frühstadien der Herzmuskelnekrosen am Paraffinschnitt. Z. Rechtsmed., 103 (1990) 199-206.

2 I. Pedal and J. Hülle, Immunenzymatische Bestimmung des $\mathrm{ABO}$ - und Sekretorstatus an paraffin eingebettetem Autopsiematerial. Z. Rechtsmed., 93 (1984) 289-300.

3 1. Ishiyama, M. Mukaida, T. Yoshii and H. Suyama, Histochemical demonstration of methamphetamine by immunocytochemistry. J. Forensic Sci., 32 (1987) 658-672.

4 I. Ishiyama, M. Mukaida, R. Tanabe, M. Kaiho and M. Ueyama, Histochemical demonstration of phenobarbital by immunocytochemistry. J. Forensic Sci., 32 (1987) 1221-1234.

5 M. Nagao, T. Takatai, B. Wu, K. Terazawa, H. Gotouda and H. Akabane, Immunohistochemical localization of paraquat in lung and brain. Med., Sci. Law., 31 (1991) 61-64.

6 G. Fechner, M. Hernandez, T. Bajanowski, M.A. Sepulchre and B. Brinkmann, Immunohistochemical alterations after muscle trauma. Int. J. Leg. Med., 105 (1993) 203-207.

7 1. Pedal and C. Baedecker, Immunenzymatische Darstellung der Isoantigene $A, B$ und $H$ in fäulnisverändertem Nierengewebe. Z. Rechtsmed., 94 (1985) 9-20.

8 P. Betz, A. Nerlich, J. Wilske, J. Tübel, I. Wiest, R. Penning and W. Eisenmenger, Immunohistochemical localization of fibronectin as a tool for the age determination of human skin wounds. Int. J. Leg. Med., 105 (1992) 21-26.

9 P. Betz, $\Lambda$. Nerlich, J. Wilske, J. Tübel, I. Wiest, R. Penning and W. Eisenmenger, The timedependent rearrangement of the epithelial basement membrane in human skin wounds immunohistochemical localization of collagens IV and VII. Int. J. Leg. Med., 105 (1992) 93-97.

10 P. Betz, A. Nerlich, J. Wilske, J. Tübel, I. Wiest, R. Penning and W. Eisenmenger, The temporary pericellular expression of collagen type IV, laminin, and heparan sulfate proteoglycan in myofibroblasts of human skin wounds. Int. J. Leg. Med., 105 (1992) 169-172.

11 P. Betz, A. Nerlich, J. Wilske, J. Tübel, R. Penning and W. Eisenmenger, The time-dependent reepithelialization of human skin wounds - immunohistochemical localization of keratins 5 and 13 . Int. J. Leg. Med., 105 (1993) 229-232.

12 P. Betz, A. Nerlich, J. Tübel, R. Penning and W. Eisenmenger, The meaning of the immunohistochemical localization of collagens type III and $\mathrm{V}$ for the time-estimation of human skin wounds. Int. J. Leg. Med., 105 (1993) 329-332.

13 W. Eisenmenger, A. Nerlich and G. Gluck, Die Bedeutung des Kollagens bei der Wundaltersbestimmung. Z. Rechtsmed., 100 (1988) 79-100.

14 S.M. Hsu, L. Raine and H. Fanger, A comparative study of the peroxidase-antiperoxidase method and an avidin-biotin complex method for studying polypeptide hormones with radio immunoassay antibodies. Am. J. Clin. Pathol., 75 (1981) 734-739.

15 S. Berg, Die Altersbestimmung von Hautverletzungen. Z. Rechtsmed., 70 (1972) 121-135.

16 J. Raekallio, Enzyme Histochemistry of Wound Healing, Fischer, Stuttgart, 1970. 